\title{
Edmund Husserl y Jan Patočka sobre la idea de Europa: primeras divergencias
}

\author{
Agustín SERRANO DE HARO \\ Instituto de Filosofía (CSIC)
}

1. Más que la coincidencia de ser coterráneo de Husserl, coincidencia que hizo exclamar al anciano pensador: « $\mathrm{A}$ Al fin! Alumnos los he tenido de todos los confines del mundo, pero que un compatriota se acercase hasta mí..., eso aún no había ocurrido»', más que ello - digo- llama la atención en la biografía intelectual de Jan Patočka su condición de discípulo de Husserl tan tardío que ya no ha sido formado directamente por el maestro. La estancia de Patočka en Friburgo en el semestre de verano del año 1933 se convirtió, a instancias del propio Husserl, en un aprendizaje de la Fenomenología bajo la tutela de Eugen Fink. Antes, un jovencísimo Patočka había escuchado a Husserl en La Sorbona, en 1929. Después lo hará en Praga en noviembre de 1935, en la última aparición pública del pensador. Y hasta el año 1937 se sucederán breves encuentros friburgueses con motivo de los intentos del Círculo filosófico de Praga de poner a salvo en la capital bohemia los infinitos manuscritos científicos de Husserl, y acaso a la propia familia Husserl.

Este peculiar discipulado, en fechas políticamente tan graves, filosóficamente tan creadoras, tiene sin duda que ver con la comprensión de la Fenomenología que Patočka propugnará; quizá incluso con el

${ }^{1}$ Jan Patočka, «Erinnerungen an Husserl», VIII-IX, en Die Welt des Menschen. Die Welt der Philosophie. Festschrift für Jan Patočka. La Haya, M. Nijhoff, 1976. La traducción es mía. 
esfuerzo por hallar una síntesis entre las versiones husserliana y heidegeriana de la misma, empresa que Patočka asumió de por vida, consciente de que la filosofía de Heidegger era una alternativa para el pensamiento fenomenológico. En todo caso, es el ámbito de problemas planteados en La crisis de las ciencias europeas -a cuya publicación parcial en Belgrado, a fines de 1936, también colaboró activamente el joven Patočka- el centro de referencia del filósofo checo. Al contrario que los discípulos de Gotinga y en menor medida de Friburgo en los años veinte, el coterráneo de Husserl reflexionará sobre el sentido de la filosofía fenomenológica a la luz de la idea de Europa y de la profundidad de su crisis espiritual. En su forma final, cuarenta años después de su encuentro con Husserl, esa reflexión se interpreta a sí misma como un "ensayo herético".

2. Si toda herejía supone un credo de referencia que sea parcialmente compartido, no es claro que la mentada en el título de la obra máxima de Patočka: Ensayos heréticos sobre la filosofía de la Historia², disienta sólo de la filosofía fenomenológica, aunque sin duda también de ella. El desarrollo de los Ensayos heréticos sí deja entrever que el credo común de referencia abarca, desde luego, la filosofía husserliana de la Historia.

Me atrevería a fijar el acuerdo de partida en la tesis husserliana de que la Historia de Europa tiene un origen único: Grecia, y en la afirmación formal de que este origen da sentido por sí solo al íntegro devenir histórico de Europa, que en realidad es el de la Humanidad. Pues también comparte Patočka la comprensión de que la Historia no es un hecho natural, ni una posibilidad dada con toda cultura humana.

La apertura a la Historia, la apertura de la Historia, tiene lugar, según el fundador de la Fenomenología, gracias a la aparición de un telos único: «la forma 'filosófica' de existencia», en la expresión de

${ }^{2}$ Traducción, de la versión francesa, de Alberto Clavería. Barcelona, Península, 1988. 
La crisis; «la cultura de Ideas», en la fórmula de La Conferencia de $V i e n a^{3}$. Sólo esa forma de existencia, sólo esta cultura peculiar alienta la aspiración a una configuración racional de la vida humana. Y sólo ellas asumen que tal configuración se ha de sostener en la lucidez intelectual plena acerca de lo que es y vale, y acerca de la razón que así lo determina en evidencia: «que todo venga de la visión»".

A juicio de Husserl, sólo este telos, que es infinito -es, pues, un ideal, mejor: el ideal de la razón-, presta unidad, continuidad, sentido, a los fines en el tiempo del individuo y las sociedades europeas. Sólo él apela como motor de la acción humana a la responsabilidad, haciendo de la evidencia intelectual el correlato originario de la libertad. Y sólo este fin de fines puede alumbrar, merced a la crítica universal, lo que en la cultura y en la política es y debe ser rector. En suma, a partir de y en función del telos ideal de racionalidad universal, hay un proceso consciente que llamamos, con término geográfico, Europa, y con su término propio, Historia. La génesis griega de la razón-ya que no hay razón mientras no se reconoce como tal y no se acepta libremente como fin-, introduciría en el principio de la Historia un fin que da sentido, ya siempre, al tiempo intersubjetivo.

Es sabido que La crisis describe esta situación originaria negando que Grecia sea una variación cultural, la "ola" helénica en el océano de las culturas que bañan efímeramente las playas del tiempo. Frente a los "meros tipos antropológicos": China, India, Persia, etc., Grecia y con ella Europa definirian "la idea absoluta" ${ }^{\text {"5 }}$. Pues bien, una primera divergencia digna de reseña, afecta a esta alteridad cultural, al

${ }^{3}$ La crisis de las ciencias europeas y la fenomenología trascendental, 5, 324. Cito por la edición de Husserliana VI, La Haya, Nijhoff, 1954, que reproduce asimismo el texto de la Conferencia de Viena: La crisis de la Humanidad europea y la filosofia. Las traducciones son mías.

${ }^{4}$ Esta afortunada expresión es del propio Patočka: Platón y Europa, 39 (Barcelona, Península, 1991. Traducción, de la versión francesa, por Marco Aurelio Galmarini.) El texto completo es: «Que todo nos venga de la visión, de la intuición en el sentido de la mirada a lo que es! Tanto en el pensamiento como en la praxis, actuar siempre con claridads.

${ }^{5}$ La crisis, 14. 
orbe confuso de lo no histórico. El filósofo checo rechaza la interpretación de lo no histórico o prehelénico como lo cultural, lo espiritualmente contingente. $\mathrm{Y}$ al modo hegeliano observa en las civilizaciones orientales: China, India, y sobre todo Babilonia, Israel, una estructura de sentido cuyo análisis resulta esencial para perfilar la inaudita anomalía griega.

Las culturas prehelénicas vivirían, de acuerdo con Patočka, en la creencia, protocreencia, de que el sentido está dado y de que este sentido declara la precariedad de la existencia humana sobre el fondo oscuro de la menesterosidad general de la vida. La vida se halla ante el incesante requerimiento a proveerse de lo necesario a la subsistencia; está siempre en trance de apagarse, encadenada a sí misma, a su alimentación perpetua. Y este destino general de la vida se hace consciente en el trabajo del hombre por producir y conservar los bienes naturales que ha de consumir. Las culturas orientales son, sin excepción, culturas del trabajo organizado, bien entendido que el trabajo en sentido antiguo difiere tanto de la producción moderna, como de la mera supervivencia animal. La regulación del tiempo, la selección de objetivos, el manejo de útiles que obran sobre el medio y acotan el espacio intuido, la organización colectiva, todo ello hace del trabajo una faena de la libertad, tarea del ser en el mundo. De una libertad, de un ser en el mundo, que, eso sí, se experimenta a sí mismo en precario, atado a un destino que viene marcado por la condición consuntiva de los bienes que alimentan "el fuego de la vida" y que, al cabo, únicamente aplazan su extinción.

A las civilizaciones antiguas del trabajo organizado pertenece, en consonancia, la expresión del mundo a través del mito. Ya que el mito repite, en modulaciones variables, una sola verdad, a saber: que el mundo pertenece a los dioses, esto es: a los que no encuentran su libertad uncida al trabajo, ni hacen de la vida aplazamiento de la muerte. No es que los dioses estén por ello ociosos; es que tienen otro cometido, más grave e indeclinable: el de velar por el orden del mundo, preservar el imperio del bien amenazado por las fuerzas ocultas y por la degradación inevitable de todo lo que existe. De este cometido los dioses hacen partícipes a los mortales. A la eterna lucha 
cósmica de los poderes del orden contra los de la tiniebla contribuye el trabajo de los hombres, y coadyuva sobre todo el gobierno de la colectividad, que recae en el único hombre libre: emperador, rey, sumo sacerdote. El que gobierna resulta por ello un ser intermedio entre lo divino y lo humano.

En todo caso la comunidad de hombres y dioses revela que dentro del cosmos «no hay ninguna zona específicamente humana del ente, ninguna región reservada al hombre y a su aspiración de responder de sí mismo: nada se parece menos a ello que los imperios de los hombres" ${ }^{6}$.

El análisis de Patočka de este sentido global, "modesto, pero seguro", que todo individuo acoge y repite, ofrece, pues, un cuadro unitario de las culturas pregriegas. En ellas la existencia humana resulta excéntrica respecto de las potencias que deciden su suerte. De aquí que sean precisamente culturas prehistóricas en una acepción rigurosa, que las opone, de una parte, a los pueblos y tribus nómadas o animistas, sin Historia, y de otra a la existencia histórica griega ${ }^{7}$. En una acepción que evita por tanto relegarlas, como hace Husserl, al magma confuso de lo espiritualmente contingente.

3. Con todo, el interés de esta divergencia inicial radica en la luz que proyecta sobre la génesis del mundo griego. Esta segunda vertiente del problema sí constituye, a mi juicio, una "herejía" significativa respecto de la interpretación husserliana. Patočka no comparte la tesis de que la teoría como interés universal por la verdad sea «el protofenómeno de la Europa espiritual» que quiebra la instalación natural del hombre en la vida y en el mundo. El horizonte de sentido previo, el que reunía a hombres y dioses en el hogar colectivo de los imperios, se habría disipado antes de la filosofía, en el momento histórico en que los hombres se han

\footnotetext{
${ }^{6}$ Ensayos heréticos, 83

' Esta distinción tripartita es también de clara ascendencia hegeliana. Patočka reconoce, por otra parte, lo mucho que debe su perspectiva a los análisis de Hannah Arendt, ante todo a La condición humana.
} 
reunido para procurar, no ya por la subsistencia, sino por el futuro libre de la polis. El protofenómeno histórico residiría en el cuidado de la comunidad política por la libertad, y en la discusión y decisión a que esa libertad urge. Pues aquí el ciudadano, no ya el hombre, ha abandonado de hecho el suelo modesto y seguro que garantizaba el mito, y se deja medir por la problematicidad radical del futuro colectivo. No se trata sólo de que todo venga a depender de las iniciativas que los ciudadanos iguales discuten en el ágora y ponen en práctica en las empresas comunes, sino también de que, en este respecto, en el respecto de la ruina o la libertad de la polis, faltan siempre intelecciones apodícticas. Es, pues, la política, antes que la teoría, la que libera hombres del trabajo, de «la base sólida de la continuidad generativas, y la que crea un dominio o espacio público que da sentido a la existencia del hombre en integridad. Ella es, en definitiva, la que gesta la nueva dimensión de la Humanidad, el eón de la Historia en que la vida humana se tiene a sí misma en integridad ante la libertad.

Cierto es que esta prioridad de la vida política sobre la actitud filosófica es, en último análisis, casi simultaneidad. Una motivación intrínseca e inmediata vincula ambas formas. Diríamos, de nuevo hegelianamente, que sólo quien ha arriesgado la vida por la libertad está en condiciones de responder, o más bien está en situación de preguntar explícitamente tí tó ón: ¿qué es el mundo en verdad y en totalidad, y cúal el lugar del hombre y cuál el régimen en que los hombres pueden convivir según el sentido de su ser?

El desafío inaudito en que consiste la democracia política se torna, en la filosofía, desafío lanzado al ser en totalidad a que revele su verdad. El primer filósofo consciente no sería entonces Tales, nombre propio del primer geómetra, tal como Husserl concede acríticamente a la tradición, sino, más bien, Heráclito, que al logos denominó pólemos, ley superior que reúne a los ciudadanos en el conflicto de la polis y a las potencias cósmicas contrapuestas en el aparecer global del mundo:

«Así, pues, pólemos es al mismo tiempo lo que engendra la ciudad y el entrever original que hace posible la filosofía.» 
"Pólemos no es la pasión devastadora de un invasor salvaje, sino lo que crea unidad. Y la unidad que crea es más profunda que cualquier simpatía efímera o cualquier coalición de intereses. Los adversarios se encuentran en la perturbación del sentido dado y crean entonces un nuevo modo de ser del hombre, quizá el único que en la tempestad del mundo ofrece esperanza, a saber: la unidad de los perturbados que, sin embargo, se enfrentan al peligro sin temor. Es también en la filosofía donde creía Heráclito hallar la unidad y el origen común de la ciudad." ${ }^{8}$

4. La gestación conexa de política y filosofía determina una "perturbación" definitiva del estado o actitud naturales. La Historia es la salida de la actitud natural. Cuestionar el acierto de semejante perturbación equivaldría, para el filósofo checo, a dudar de la conveniencia de abandonar la infancia. Así y todo, tras esa quiebra el hombre tiene mucho que ganar, mucho que perder: cantidades, si cabe la expresión, que han de medirse en unidad o patrón de sentido. Ahora bien, esta aurora política y filosófica de la Historia en el siglo sexto aún no determina cuál es el asunto específico del devenir de Europa, del mediodía de la Humanidad. Para ello hay que esperar al siglo quinto, en especial a "los hermanos enemigos" Demócrito y Platón. Ambos definen ese asunto, esa cuestión como epimelesthai tes psychés: cuidado o preocupación por el alma, entendiendo por alma «lo que en el hombre es capaz de la verdad» y lo que a través de la verdad «llega a ser lo que puede ser».

En el análisis patočkiano, el salto espiritual e histórico del siglo quinto descansa asimismo sobre una pluralidad de motivos conexos. Por una parte, la experiencia primigenia de la totalidad del ser en forma de presencia imperante de la physis deja ahora sitio al interés analítico por la concreción del mundo y por la estructura "eterna" de los entes. $\mathrm{Y}$ análisis quiere decir reflexión sistemática, argumentación en forma, progreso teorético, ciencia. A la vez, el alma, de cuyo cuidado se trata, no se concibe ya - ni en el atomismo democríteo, ni

${ }^{8}$ O. c., 64. 
en la meditación platónica - en la forma del alma inmersa en el ciclo orgánico o sujeta al arcano de los misterios, el alma-sombra, etc. A partir de ahora, el alma es "el alma que yo mismo soy» y la filosofía podrá proclamar - valga el anacronismo-: res tua agitur?.

Ambas modificaciones de sentido, "cosmológica" y "psicológica”, revierten sobre la articulación de la polis. Sobre ésta pesa ahora la exigencia de una ordenación de la vida humana que haga posible la epimelesthai tes psychés, la vida en orden a la verdad. La filosofía, que medita públicamente sobre la justicia, entra así en diálogo y en conflicto con los poderes que pretenden apropiarse la definición de la grandeza y de la gloria.

Este complejo de transformaciones en las ideas de la razón culmina en una última dimensión del cuidado del alma, a saber: en la meditación que quiere ser responsable, no orgiástica, acerca del destino y sentido definitivos del alma; escatología platónica, que, según Patočka, guiará la incorporación del judaísmo al telos europeo: una incorporación, portanto, necesariamente helenizada, platonizada.

Patočka está lejos de afirmar que el cuidado del alma sea la fuerza motriz de la Historia europea. No se trata de su causa eficiente; en todo caso, de su causa formal, de su tema, de su asunto y de la dinámica que le es propia. Asunto de la verdad y dinámica de paideia, que, eso sí, «entra en el círculo de todas las posibilidades humanas desde el momento en que emerge en tanto posibilidad ${ }^{10}$, y que además hace posible una herencia por sobre las quiebras del acontecer histórico. De hecho, es la vertiente política del cuidado del alma la que sufre repetidos fracasos, que Patočka eleva a la consideración de catástrofes: catástrofe de la polis que elimina al hombre que a todas horas convocaba a tal cuidado; catástrofe, luego, del helenismo y del Imperio de Roma, incapaces de regular jurídica y universalmente el ejercicio del poder; y en fin, frustración posterior del Imperio romano germánico. Los sucesivos fracasos denotarían, con todo, una

${ }^{9}$ En relación con toda esta problemática, es obligado consultar la obra anterior a los Ensayos heréticos: Platón y Europa.

${ }^{10}$ Platón y Europa, 69. 
continuidad inteligible de la aspiración europea a vivir en la verdad y a afirmarse en esta forma de vida frente a las formaciones históricas concurrentes: el Islam, atado a un profetismo particularista, y el Oriente bizantino, que impera, cruz y corona unidas, sobre el alma y el cuerpo de los hombres.

5. Valga la mención de estas líneas de fuerza de la matizada reflexión del pensador checo para perfilar algunos contrastes con la filosofía de la Historia de su maestro. Llama la atención el hecho de que ambos pensadores subrayan con enorme énfasis la ruptura inaudita que significa el ideal de la razón (y que impide definitivamente hablar de filosofías orientales, de ciencia en actitud natural e incluso de saber profético de salvación), no siendo, sin embargo, sus respectivos en-foques conceptuales enteramente equivalentes. Donde Pato_ka habla de una perturbación respecto de la vida natural precedente, Husserl habla ya desde el nuevo presente y del nuevo presente como una protofundación o protoinstauración. Donde el checo cree obligado hablar de desafio, de riesgo, el fundador de la Fenomenología describe el proyecto europeo de siglos como tarea infinita y misión abierta, en realidad nunca clausurable. Esta disparidad en los términos oculta, en mi opinión, una diferencia teórica relevante.

Ocurre que en el caso de Husserl la emergencia del telos ideal proporciona eo ipso sentido y amparo al hombre, siquiera sea un sentido que desde el futuro de racionalidad cumplida se proyecta hasta el presente de la tarea de racionalización. Quien se convierte a la vida teorética se ubica ya, de algún modo, en ambas fronteras temporales. La aparición del telos y el habitar humano en él es todo uno, como si el acto de dar sentido a la Idea de la razón y a su valor normativo sobre la vida entera asegurase de antemano ese suelo que en la posición de Pato_ka sólo podía recuperar, si acaso, la paideia del alma en busca y cultivo de sí misma.

La virtualidad infinita que el ideal despliega en todos los órdenes de la vida, y que Husserl tan vivamente destaca, no cuestiona, al contrario, confirma que el acto de afirmación de la libertad racional 
no sólo es autónomo, sino, por así decir, autárquico. El cuidado del alma como introducción, quizá de por vida, al régimen desconocido y también precario de vida en la verdad, acaso no tendría para el maestro de Patočka más que la modesta función de conservar o recordar el impulso original de una libertad que se activa y se alimenta a sí misma. En el alba de la Historia, o mejor, como el comienzo de la Historia, la libertad habría reconocido su único fin posible y de esta forma se habría ya recuperado a sí misma; habría ganado en el movimiento inicial hacia el ideal de teoría el concepto esencial de sí.

No es de extrañar, así las cosas, la ausencia casi completa en las meditaciones husserlianas de análisis sobre las formas políticas europeas, sus innovaciones y sus fracasos. Lo político resulta filosofía segunda, es decir, filosofía primera aplicada. O dicho de otro modo, Husserl no parece necesitar de la conceptuación hegeliana del Estado, que a la altura de cada época unifica la voluntad subjetiva con la voluntad racional y de este modo realiza el designio histórico de la razón. Entre la libertad individual, que aquí no está entreverada de raíz con pasiones e impulsos, y la Idea vinculante, que, por tanto, no precisa de la astucia, no hay ningún término intermedio, ninguna configuración cultural, ningún desarrollo dialéctico.

Este contraste innegable de la persepctiva husserliana con la de Patočka, con la del propio Hegel, mueven a pensar si la meditación husserliana sobre la Historia no es al cabo monista. Monista en el sentido de que sólo conoce un motor histórico: la libertad racional, y un motivo operante sobre él: la racionalidad, o mejor, apodicticidad. Los fracasos de las políticas democráticas frente al poder injustificado, el sufrimiento sordo, la injusticia irreparable, tendrán, en su perspectiva, alguna realidad, si bien -y esto es lo decisivo- su grado de realidad se describe cabalmente por la ausencia del único principio dinámico que es configurador. El envés de la Historia no responde, pues, a ninguna categoría. Ese envés, que también Husserl experimentó penosamente en los últimos años de su vida, parece caer en su reflexión, asimismo, del lado de lo contingente. ¿Cómo, si no, se justifica esa asombrosa síntesis a priori que Husserl proclama: «Las 
Ideas son más potentes que los poderes fácticos» ${ }^{11}$, sin revelar, empero, su origen, ni «deducirla trascendentalmente»?

6. Las diferencias teóricas entre Husserl y su brillante discípulo checo desembocan en una divergencia completa, oposición casi contradictoria, a la hora de interpretar el sentido de la Edad Moderna. La tesis de Patočka de que la Edad Moderna, o la tendencia predominante en ella significa el arrumbamiento del cuidado del alma en favor de una empresa alternativa: la del dominio del mundo, acerca su posición a la de Heidegger. La tesis de Husserl es, en cambio, que en su constitución programática Renacimiento y Edad Moderna significan el resurgir, por principio autónomo, de la Idea de la Razón. Así, donde Patočka prima la pugna política y militar de las potencias europeas que luchan por la hegemonía y excluyen toda idea espiritual vinculante entre las naciones, destaca Husserl el afán de reforma completa de todos los órdenes de la vida humana, sobre todo de la educación. Y mientras el pensador bohemio entiende la movilización de todas las energías, naturales y humanas, como un destino suprateórico que alcanza expresión en el lema baconiano: saber es poder, el maestro moravo defiende que son la unilateralidad, las oscuridades de la ontología galileana, es decir, insuficiencias teoréticas, las que rebajan la ciencia a técnica, la filosofía a matemática, el saber a positivismo. ${ }^{12}$

Esta controversia de principio acerca del sentido de la Modernidad es sin duda cuestión de la máxima relevancia y actualidad. Y no hay por qué suponer que la situación objeto de análisis no sea esencialmente más ambigua de lo que plantean las interpretaciones que estoy cotejando. Por mi parte, hay una última cuestión previa que

${ }^{11}$ La crisis de la Humanidad europea y la filosofia, 335.

${ }^{12} \mathrm{Si}$ nos servimos del esquema propuesto por Habermas en El discurso filosófico de la Modernidad, Patočka quedaría ubicado, mal que bien, entre los seguidores de Nietszche, que en su interpretación de la Edad Moderna desafían igualmente a la derecha y a la izquierda hegelianas. Claro que en ese esquema es difícil insertar la perspectiva husserliana si no es como reafirmación, bien que heterodoxa, del hegelianismo original. 
quiero destacar. Se trata de cómo a ojos de Husserl el ideal moderno carece íntegramente de novedad; más que de una renovación, se trataría de una repetición -Husserl recurre de hecho a este término-: repetición estricta de la Idea que había abierto la Historia y que la reabre de nuevo en otra encrucijada temporal. (De hecho la propia Fenomenología trascendental se entiende a sí misma como una postrera reapertura del telos de la apodicticidad.) Pero repárese bien en el hecho de que en conceptos ontológicos esto significa que en el continuo del tiempo cabe, más que una vuelta al origen, una vuelta "del" origen; una instauración literal del principio, auténtica repetición, contra lo que Kierkegaard creyó.

No parecería arbitrario poner en relación la filosofía husserliana de la Historia con la teoría fenomenológica de los objetos ideales. Esta Idea de la Razón no es susceptible de multiplicarse, ni siquiera de modularse de modo vario en un círculo de variación, y por supuesto no es sujeto posible de mudanza. Su parecido con la unidad ideal que es cada proposición en sentido lógico y cuya identidad se mantiene por sobre los múltiples actos de juicio iguales, es sin duda esencial. Ocurre, empero, que la Idea de la Razón estaba llamada a ser el principio histórico-genético, histórico-poiético, y, por tanto, no puede soslayarse la pregunta de en qué sentido el proceso histórico es verdaderamente una secuencia temporal, una cadena o serie de irrepetibilidades irreversibles e irrevocables, individualidad absoluta. ¿ está más bien en el tiempo sólo la decepción recurrente y misteriosa del Ideal de la Razón, esa capa de contingencia que arrastra el telos pero que en nada condiciona su vigencia? ¿No consistirá al fin "el heroísmo de la razón", al que Husserl convoca, en la osadía de afirmar tal pretensión y en hacerla valer frente al "cansancio" que genera aquella contingencia? Pero entonces, más que apuntar a una utopía de la razón, la filosofía husserliana de la Historia descansaría en una suerte de presente eterno de la libertad racional que siempre está en condiciones de reeditar, como en la aurora del saber, el fin de todos los fines. 